Société d'histoire de la révolution de 1848 et des

révolutions du XIXe siècle

$37 \mid 2008$

L'ère victorienne revisitée

\title{
Yves DÉLOYE et Olivier IHL, L'acte de vote
}

Jean-Claude Caron

URL : http://journals.openedition.org/rh19/3524

DOI : $10.4000 /$ rh19.3524

ISSN : $1777-5329$

Éditeur

La Société de 1848

Édition imprimée

Date de publication : 15 novembre 2008

Pagination : 185-242

ISSN : 1265-1354

Référence électronique

Jean-Claude Caron, "Yves DÉLOYE et Olivier IHL, L'acte de vote », Revue d'histoire du XIXe siècle [En

ligne], 37 | 2008, mis en ligne le 01 décembre 2008, consulté le 22 septembre 2020. URL : http://

journals.openedition.org/rh19/3524; DOI : https://doi.org/10.4000/rh19.3524

Ce document a été généré automatiquement le 22 septembre 2020.

Tous droits réservés 


\title{
Yves DÉLOYE et Olivier IHL, L'acte de vote
}

\author{
Jean-Claude Caron
}

\section{RÉFÉRENCE}

Yves DÉLOYE et Olivier IHL,L'acte de vote, Paris, Presses de Sciences-Po, 2008, 567 p. ISBN : 13-978-2-7246-1058-1. 20 euros.

1 Cette somme en forme de synthèse intéressera tous ceux que l'histoire électorale, l'histoire de la citoyenneté et, au delà, l'histoire des pratiques politiques passionnent. L'histoire des élections, du système électoral et des pratiques de vote constitue un domaine de recherche en soi où se croisent les approches et les points de vue : parmi d'autres, on sait ce que, dans la bibliographie de langue française, les noms de Patrick Lagoueyte, Michel Offerlé, Raymond Huard, Alain Garrigou, Pierre Rosanvallon, Philippe Braud, Daniel Gaxie, Annick Percheron, Alain Lancelot représentent en ce domaine, renouvelé par les apports de Christophe Voilliot, Nathalie Dompnier, Éric Phélippeau ou encore Philippe Tanchoux. Entre sociologie, science politique et histoire, l'élection constitue un terrain privilégié de rencontres entre disciplines. Cet ouvrage représente une contribution majeure à l'histoire matérielle de la démocratie à travers quatre grandes parties : le rituel du vote (une mise en scène politique, l'ingénierie du vote universel, l'urne électorale); les règles du jeu (l'invention de la représentation proportionnelle, des voix pas comme les autres, les fraudes électorales) ; la citoyenneté électorale (gouverner les citoyens, la civilité électorale, socialisation religieuse et comportement électoral en France) ; les nouveaux défis de la représentation politique (l'élection au village, le recrutement politique, sur les usages des dispositifs de vote). Le simple énoncé de ces thèmes ne rend pas justice à la densité de l'ouvrage, qui mélange problématique, analyse et exemples, souvent pris dans l'histoire du XIX siècle, domaine de prédilection des deux auteurs. On rappellera qu'Yves Déloye a récemment publié Les voix de Dieu. Pour une autre histoire du suffrage électoral: le clergé catholique français et le vote $\left(X X^{e}-X X^{e} \text { siècles }\right)^{1}$ et qu'Olivier Ihl est l'auteur d'un manuel reconnu sur 
Le Vote et l'auteur de notices dans le Dictionnaire des élections européennes dirigé par Yves Déloye $^{2}$. Nourri d'expériences étrangères et d'une réelle interdisciplinarité, cet Acte de vote donne à voir la matérialité de l'élection dans toutes ses composantes. L'historicité adoptée ici se combine avec une approche sociologique et politiste qui, au travers des thèmes retenus, donne un sentiment double au lecteur : à la fois une familiarité avec des pratiques qui appartiennent toujours au répertoire du vote et un éloignement temporel avec d'autres qui semblent inactuelles. Au total, un ouvrage riche qui ouvre des perspectives de recherche au plan national comme au plan local.

\section{NOTES}

1. . Yves Déloye, Les voix de Dieu. Pour une autre histoire du suffrage électoral: le clergé catholique français et le vote (XIX'-XX ${ }^{e}$ siècles), Paris, Fayard, 2006. Voir le compte rendu de Christophe Voilliot dans la Revue d'histoire du XIX ${ }^{e}$ siècle, $\mathrm{n}^{\circ}$ 34, 2007, p. 177-180.

2. Olivier Ihl, Le vote, Paris, Montchrestien, 2000 ( $2^{\mathrm{e}}$ éd.); Yves Déloye [dir.], Dictionnaire des élections européennes, Paris, Economica, 2005. 